\title{
Application of evidence on probiotics, prebiotics and synbiotics by food industry: a descriptive study
}

Mary N Mugambi ${ }^{1 *}$, Taryn Young ${ }^{2}$ and Reneé Blaauw ${ }^{1}$

\begin{abstract}
Background: This study assessed how the food industry applies the knowledge and evidence gained from synbiotics, probiotics or prebiotics research in infants, on the general paediatric population. This study also explored: what happens after the clinical trials using infant formula are completed, data is published or remains unpublished; the effectiveness and type of medium the formula manufacturers use to educate consumers on probiotic, prebiotic or synbiotic infant formula.
\end{abstract}

Findings: This was a descriptive study (a survey) that used a structured questionnaire. All listed companies that manufacture and / or market food products with added probiotics, prebiotics or synbiotics for infants were identified and invited to participate. People responsible for research and development were invited to participate in the survey. A letter of invitation was sent to selected participants and if they expressed willingness to take part in the study, a questionnaire with a written consent form was sent. Descriptive statistics and associations between categorical variables were to be tested using a Chi-square test, a $\mathrm{p}<0.05$ was statistically significant.

A total of 25 major infant formulas, baby food manufacturers were identified, invited to participate in the survey. No company was willing to participate in the survey for different reasons: failure to take any action $5(20 \%)$, decision to participate indefinitely delayed $2(8 \%)$, sensitivity of requested information $3(12 \%)$, company does not conduct clinical trials 1 (4\%), company declined without further information 4 (16\%), erroneous contact information 6 (24\%), refusal by receptionists to forward telephone calls to appropriate staff $3(12 \%)$, language barrier $3(12 \%)$, company no longer agrees to market research 1 (4\%).

Conclusion: Due to a poor response rate in this study, no conclusion could be drawn on how the food industry applies evidence gained through probiotics, prebiotics or synbiotics research on infants for the benefit of the general paediatric population. More information and greater transparency is needed from the infant formula manufacturers on how they apply the evidence gained from the research on probiotics, prebiotics and synbiotics on infants.

Keywords: Food industry, Infant formula, Evidence, Probiotics, Prebiotics, Synbiotics

\section{Background}

Scientific evidence from numerous studies in the last 25 years confirms that breastfeeding is the optimal way to feed infants, since breast milk contains all the essential nutrients to meet babies' needs, as well as antibodies that fight off infection [1-4]. The World Health Organisation (WHO) estimates, that if women breastfed their infants,

\footnotetext{
* Correspondence: nkmugambi@hotmail.com

1 Division of Human Nutrition, Faculty of Medicine and Health Sciences, Stellenbosch University, Stellenbosch, South Africa

Full list of author information is available at the end of the article
}

up to 1.5 million infant deaths or $13 \%$ of deaths in children under 5 years old could be prevented annually [5]. Despite the benefits of breastfeeding, more women are choosing formula feeding, either exclusively or giving mixed feeds (both formula and partial breastfeeding). Globally, this has resulted in sales of infant formula skyrocketing creating stiff competition among infant formula companies to manufacture new and innovative products [5].

A factor driving research and innovation in the infant food industry is the need to understand the composition 
and functional characteristics of breast milk. Therefore, scientists continuously conduct research to identify how infant formula can be adapted to more closely resemble the composition and function of human milk. This has resulted in different components being added to infant formula such as docosahexaenoic acid (DHA), arachidonic acid, synbiotics, probiotics or prebiotics [6-9].

\section{Probiotics, prebiotics and synbiotics}

Probiotics are defined as "live microorganisms" which when administered in adequate amounts may confer a health benefit to the host. [9-11] The main probiotics used worldwide are Lactobacillus and Bifidobacteria which are found in the gastrointestinal (GI) microflora $[11,12]$. Formula companies have been adding probiotics to infant formula [11-16].

Prebiotics are non- digestible food ingredients that may benefit the host by selectively stimulating the growth and/or activity of one or a limited number of bacteria in the colon and improving the host's health $[9,10,17,18]$. The most widely studied prebiotics are inulin and fructooligosaccharide (FOS) which are added to different foods as fat and sugar replacements to improve texture or for their functional benefits $[9,10]$. The latter is why formula companies now add prebiotics to infant formula. Adding prebiotics to formula stimulates the growth of only beneficial bacteria in the gastrointestinal tract to levels found in breastfed infants [17-19].

When probiotics and prebiotics are administered simultaneously, the combination is termed Synbiotics $[9,10,19]$. A new trend in the infant food industry is the addition of synbiotics to infant formula.

\section{How strong is the evidence for adding probiotics, prebiotics and synbiotics to infant formula?}

There is evidence that a healthy GI microflora in infants is necessary to achieve optimal health and growth [20]. For infants who are not breastfed, there is a rational to adapt infant formulas to promote an intestinal microbiota resembling that of breastfed infants, which has greater concentration of bifidobacteria, fewer potentially pathogenic bacteria than formula fed infants. This is achieved by adding probiotics, prebiotics or synbiotics to infant formula for full term and preterm infants [11]. Adding these ingredients to infant formula changes the intestinal microbiota of infants $[19,21,22]$.

Systematic reviews of randomized clinical trials offer the highest level of evidence for information on the effectiveness of an intervention [23-25]. Systematic reviews on full term infants given probiotics show certain strains of probiotics improve stool consistency and frequency (Lactobacillus GG) [26], other strains increase average formula intake (L. reuteri, B. lactis) [22], and support normal growth (B. lactis, B. longum BL999, L. rhamnosus
LPR, Lactobacillus GG, L. reuteri ATCC 55730) [26]. For preterm infants, administration of probiotics results in reduced risk of Necrotising Enterocolitis (from combinations of Lactobacillus bifidus, streptococcus thermophillus, and bifidobactrium infantis) and mortality (L acidophilus and $B$ infantis) [27].

Prebiotics have a good safety record at levels found in existing food components. Flatulence or abdominal bloating are reported at doses greater than $20 \mathrm{~g} /$ day. Abdominal cramps or diarrhoea are reported at doses greater than $50 \mathrm{~g} /$ day [19]. Adding prebiotics to formula stimulates the growth of only beneficial bacteria in the gastrointestinal tract to levels found in breastfed infants and improves intestinal architecture which reduces intestinal permeability $[12,19,28-31]$.

\section{Communication of best evidence to the consumer}

The environment for communicating health and nutrition information has changed in recent years due to an increase of television, radio channels, internet usage, and new media such as social networking sites, podcasts and webinars [32]. To communicate with the consumers, the food industry uses multiple channels to promote and sell their products with a goal of achieving profitable growth. The food industry uses subtle messages of better nutrition as part of their promotional activities [33]. In the context of probiotics, prebiotics containing food products, the consumer may not understand the meaning or importance of scientific terms such as probiotics, Lactobacillus, fructooligosaccharide or inulin. Thus, there is a great need for clear information in a language that the consumer can understand.

\section{Rationale for research}

To our knowledge, there are no studies that have assessed how the food industry applies the knowledge and evidence gained from research on probiotics, prebiotics or synbiotics on the general paediatric population. This study attempted to explore what happens after research trials using infant formula have been conducted and the data is published or remains unpublished. Based on the new scientific evidence, do the companies routinely develop and market a new probiotic, prebiotic or synbiotic containing infant formula, or improve on one that is already sold on the market?

Probiotic infant formulas have been sold in Europe and Asia in the last 15 years but are not used widely in North America [34]. A physical check of several retail outlets in the Western Cape, South Africa, yielded few brands (sometimes only two) of probiotic containing infant formula. Yet several companies (in collaboration with academic institutions) have conducted research projects using probiotics and prebiotics on infants in Southern 
Africa [35,36]. There is little or no information on the differences between the study formula and the retailed product. It is not clear how the manufacturers of probiotic, prebiotic or synbiotic containing infant formula educate the consumers on their products. This study set out to answer product specific questions on genera of probiotics used, product viability at end of shelf life, differences between study and retailed product. As well as explore the effectiveness and type of medium the infant formula manufacturers use to educate the consumers on probiotic, prebiotic or synbiotic infant formula.

Safety issues are also an area of concern. The two probiotic infant formula brands available in the Western Cape, South Africa retail outlets state that using water with temperatures above $40^{\circ} \mathrm{C}$ (degrees centigrade) will compromise the natural cultures. This contradicts the WHO "Guidelines for safe preparation, storage and handling of powdered infant formula" which recommends that water with a minimum temperature of $70^{\circ} \mathrm{C}$ should be used to minimize the risk of potentially deadly infections caused by Enterobacter Sakazakii, bacteria that has been found in infant formula [37]. In addition there is a lack of published evidence on clinical benefits from long term use of probiotic containing infant formula $[26,38]$. This study tried to explore how the infant formula companies address the contradiction to WHO guidelines on formula preparation and safety issues of long term usage of probiotic infant formula.

\section{Research question}

Does the food industry apply the evidence gained through probiotics, prebiotics and synbiotics research on infants for the benefit of the general paediatric population?

\section{Research aim}

To investigate how the infant food industry applies evidence gained through probiotics, prebiotics and synbiotics research on infants.

\section{Objectives}

The objectives of this study were to determine the following:

\section{Application of evidence:}

1. If new research evidence resulted in new infant formula products been developed,

2. If there were any differences in study and retailed infant formula,

3. The frequency of conducting research using probiotics, prebiotics or synbiotics containing infant formula.
Publication of results:

4. If the infant formula companies had intentionally NOT published study results that were viewed as negative or having no clinical benefit to infants?

5. If study results perceived to be negative, were withheld and was new research conducted to confirm the results?

\section{Medium for consumer education:}

6. The type and effectiveness of medium used to educate the consumer,

7. The presence of bias in promoting formula feeding more than breastfeeding.

\section{Compliance to WHO guidelines:}

8. How formula companies complied with WHO guidelines on formula preparation with a focus on high water temperature and its effects on probiotics, synbiotics containing infant formula?

\section{Safety of long term use of probiotic or synbiotic} containing infant formula,

9. How companies addressed safety, since there is a lack of published evidence on the clinical benefits of long term consumption of probiotic containing formula (longer than 1 year).

\section{Product viability,}

10. If the probiotic, synbiotic containing infant formula remain viable throughout storage or are there substantial changes in the number of colony forming units at the end of shelf life?

How companies keep abreast of the latest research on probiotics, prebiotics and synbiotics in infant formula and weaning foods?

11. If the formula companies had staff designated to keep track of research or was it on "ad hoc" basis?

\section{Methodology}

\section{Study design}

This was a descriptive study (a survey) employing the use of a structured questionnaire developed by the researcher.

\section{Company selection}

Companies that manufacture and/or market food products with added probiotics, prebiotics or both (synbiotics) for infants and children were identified through several 
databases such as EBSCOhost, Business Source Premier and DATAMONITOR ${ }^{360}$. In addition, company websites were visited to acquire the contact information of individual companies. The person/people responsible for research and development were invited to participate in the survey. Study participants included clinical research managers and individual researchers in the infant food companies. Worldwide, the numbers of infant food companies (especially infant formula manufactures) are few. Therefore all listed companies were invited to participate in the study. The number of study participants per company was one or two.

\section{Data collection and processing}

A letter of invitation was sent to selected participants, inviting them to take part in the study. The letter of invitation explained all aspects of the study, and if they expressed willingness to take part in the study, a questionnaire with a written consent form was sent via post, email or fax. If the questionnaire was posted, a stamped envelope was included for returning the completed questionnaire to the researcher. A maximum of four reminders were given to the participants to complete the questionnaire. The participants were free to withdraw from the study at any time without any consequence.

Due to the expected small sample size, maintaining anonymity of study participants with the corresponding company name was difficult. Therefore, data processing was done according to product and company name. However, during report writing, all identifying details (name of study participant, product and company name) were excluded. Only the researcher and statistician had access to the data.

\section{Questionnaire description}

A questionnaire was designed for this study based on relevant published information. The questionnaire focused on product specific questions, research based questions, education of consumers and safety issues. It was validated for content by sending it to experts in the field of probiotics, prebiotics and infant nutrition, who were able to judge if the questionnaire met the objectives of the study. These experts did not partake in the study nor were they associated with the infant food industry.

\section{Data analysis}

Researchers planned to enter the collected data into SPSS (Statistical Program for Social Sciences) for analysis. The data was to be analysed using descriptive statistics and associations between categorical variables, be tested using a Chi-square test. A p $<0.05$ was considered statistically significant. A statistician was consulted at every step of the study process.

\section{Ethics approval}

Ethics approval to conduct this study was given by the Human Research Ethics Committee at the University of Stellenbosch, Faculty of Medicine and Health Sciences, reference number N11/07/203.

\section{Findings}

A total of 25 major infant formula and baby food manufacturers were identified from around the world and invited to participate in the survey (Table 1). A total of 5 (20\%) companies initially agreed to participate but took no action by not signing the informed consent form and completing the questionnaire. The decision to participate in the study was delayed indefinitely for $2(8 \%)$ companies since their head of department was too busy to make a final decision. Sensitivity that the requested information would give the competition an advantage was cited by $3(12 \%)$ companies for not participating in the study, while 1 (4\%) company stated they manufacture baby food and distribute it for retail without conducting any clinical trials. A total of 4 (16\%) companies declined to participate without giving any further information. Erroneous contact information given on company websites hindered any contacted being made with $6(24 \%)$ companies. Company representatives from 3 (12\%) companies refused to forward telephone calls from the researchers to the appropriate department and staff. Three (12\%) companies cited language barrier (Mandarin, German, Dutch) as a reason for not participating in the study, despite offers to professionally translate the study documents into a language of their choice. One (4\%) company stated that it was overwhelmed with people making

Table 1 List of 25 baby food companies and infant formula manufacturers invited to participate in survey

\begin{tabular}{|c|c|}
\hline Company name & Company name \\
\hline $\begin{array}{l}\text { Abbott Laboratories/Abbot } \\
\text { Nutrition }\end{array}$ & Milupa \\
\hline Aspen Phamarcare & Morinaga Milk industry Co. Ltd \\
\hline Beech-nut nutrition corporation & Nestle (South Africa and Switzerland) \\
\hline $\begin{array}{l}\text { Danone baby and medical } \\
\text { nutrition BV }\end{array}$ & Organix brands \\
\hline Earth's Best (Hain Celestian Group) & Pfizer Inc (SA) and Pfizer Head office \\
\hline FrieslandCampina (Netherlands) & Raptakos Brett \& Co. Ltd. \\
\hline Gerber products company & SMA Nutrition (Ireland and UK) \\
\hline $\begin{array}{l}\text { Hangzhou Beingmate Group } \\
\text { Co Ltd. }\end{array}$ & Synutra International \\
\hline HiPP GmbH \& Co Vertrieb KG & Tiger brands \\
\hline $\mathrm{JH} J$ Heinz & Wakodo Co. Ltd \\
\hline Kewpie & Wockhardt Limited \\
\hline Mead Johnson & Hero AG \\
\hline Meiji Dairies & \\
\hline
\end{tabular}


requests for market research, as a result it had restructured and "market research was no-longer a priority" (Table 2). In the end no company was willing to participate in the survey.

\section{Discussion}

To our knowledge, this was the first study to explore how the food industry applies evidence gained through research on probiotics, prebiotics and synbiotics on infants for the benefit of the general population. As a direct result of the poor response rate in this survey, several study objectives and key questions remain unanswered. These are discussed below.

\section{Application of evidence}

Despite more than 30 years of research on probiotics, prebiotics or synbiotics on infants and children, any differences between studied and retailed infant formula such as the strains of probiotic bacteria used could not be established. It remains unknown if new evidence from clinical trials led to the improvement of existing formula, development of new infant formula or weaning foods containing probiotics or synbiotics.

\section{Publication of results (Publication bias)}

Publication bias is defined as "the tendency for investigators, journal editors and reviewers to submit or accept a manuscript for publication based on the directions or strength of the study findings [39]. Publication bias can

Table 2 Reasons for not participating in survey

\begin{tabular}{|c|c|}
\hline Reason(s) for not participating in survey & $\begin{array}{c}\mathrm{N}=25 \\
\text { Number of } \\
\text { companies } \mathrm{n}(\%)\end{array}$ \\
\hline $\begin{array}{l}\text { No Action taken by company after agreeing to } \\
\text { participate in survey }\end{array}$ & $5(20 \%)$ \\
\hline Head of department too busy to make decision & $2(8 \%)$ \\
\hline $\begin{array}{l}\text { Requested information too sensitive - may give } \\
\text { competition an advantage }\end{array}$ & $3(12 \%)$ \\
\hline $\begin{array}{l}\text { Company does not conduct clinical trials, just } \\
\text { manufacture infant food, distribute it for retail }\end{array}$ & $1(4 \%)$ \\
\hline No reason given for declining to participate in survey & $4(16 \%)$ \\
\hline $\begin{array}{l}\text { Researchers unable to make contact with company } \\
\text { through use of internet (emails, "contact us" features } \\
\text { in company websites), telephone, fax or post office. }\end{array}$ & $6(24 \%)$ \\
\hline $\begin{array}{l}\text { Company receptionist/contact person refused to } \\
\text { forward call/put researchers in touch with } \\
\text { appropriate person to answer questions }\end{array}$ & $3(12 \%)$ \\
\hline $\begin{array}{l}\text { Quote: "Too many people conducting market } \\
\text { research on company, company has other priorities } \\
\text { than answering market research questions." }\end{array}$ & $1(4 \%)$ \\
\hline $\begin{array}{l}\text { Language barrier - "prefer questionnaire in local } \\
\text { dialect" such as Mandarin, Dutch, German. }\end{array}$ & $3(12 \%)$ \\
\hline
\end{tabular}

have far reaching consequences on the public. For example, if an intervention that is not effective is falsely considered effective and administered to patients, an effective treatment that is available is withheld. Not publishing results from research where the intervention is discovered to be harmful; may indirectly harm study participants taking part in future research. This is because other investigators will (unknowingly) repeat the same research, testing the harmful intervention, causing suffering on a different group of people [39]. This study was not able to establish if companies engaged in research had intentionally NOT published study results that were viewed as negative or not having any clinical benefits to infants and children. Whether companies conducted new research to confirm results that may have been perceived as negative could not be established.

\section{Medium for consumer education}

The type and effectiveness of medium used to educate the consumer on probiotics, prebiotics or synbiotics containing formula or baby foods could not be established. The numerous techniques used by the formula and baby food industry to increase awareness of their products are beyond the scope of this study and are described elsewhere. Only one education and promotion technique is illustrated below.

\section{Internet}

The internet is an important source of health information for parents [40-42]. Company websites offer advice on infant feeding, child rearing and health care issues. Some websites have useful product information, most websites use information on breastfeeding to jump to the second best option; formula feeding [3].

Most websites of formula manufacturers have product specific content concerning infant formula brands. Websites present images of branded packs linked with information about specific infant formula. These website links are accessible to the public, health and medical professionals. Research has shown consumers (mothers) get confused with formula advertising [40]. In situations where infant formula and follow-on formula share brand identities, consumers recall advertising and messages for follow-on formula and think it also applies to infant formula. As a result, information and promotional messages designed around follow-on formula are transferred to infant formula products. This type of confusion has far reaching implications [40].

Navigating the websites of the 25 companies invited to participate in this study, in addition to the product specific content in the websites, only eight companies had brief descriptions of probiotics or prebiotics, five companies had health claims on probiotics and one company had a health claim on prebiotics. There was no mention 
of the strains of probiotics or type of prebiotics in their products. In addition, the information on probiotics and prebiotics was difficult to obtain from the websites and could be inaccessible to consumers without advanced computer skills, tertiary education or sufficient knowledge on what to look for.

\section{Compliance to WHO guidelines}

The position of formula companies on how they comply with WHO guidelines on water temperature during formula preparation could not be established. WHO recommends diluting the powdered formula in water at a temperature of at least $70^{\circ} \mathrm{C}$ to inactivate cronobacter spp. (Enterobacter sakazakii) [37]. South Africa's "Regulations Relating to Foodstuffs for Infants and Young Children, Government Gazette number 35941" state that labels for any infant formula, follow-up formula must "provide instructions for appropriate use according to the latest FAO/WHO guidelines." The gazette requires the labels to state that infant formula is not always sterile and may contain harmful microorganisms, emphasizing appropriate preparation [43]. Yet the labels of infant formula found in retail stores of Western Cape, South Africa do not recommend using water above $40^{\circ} \mathrm{C}$.

The European Society of Pediatric Gastroenterology, Hepatology and Nutrition (ESPGHAN) committee on nutrition and French Food Safety Agency (AFSSA) disagree with WHO guidelines and state that heating water to temperatures greater than $70^{\circ} \mathrm{C}$ is not necessary and maybe harmful to the nutritional quality of formula. Using hot water (greater than $70^{\circ} \mathrm{C}$ ) may lead to formation of curds, risk of severe burns and the loss of 10 to $25 \%$ of some nutrients: Thiamine, Vitamins B1, B6, B12, Folic acid, and Vitamin C $[44,45]$. The effect of water temperature on Cronobacter spp. (Enterobacter sakazakii) is striking. At 37 to $39^{\circ} \mathrm{C}$, there is optimal growth, at 5.5 to $8^{\circ} \mathrm{C}$ there is minimal growth. At room temperature, Cronobacter spp. has the potential for rapid growth $[44,45]$. It is worth noting the rate of contamination with Cronobacter spp. has decreased over the years from $14 \%$ in 1980 s to $2.4 \%$ in mid 2000s [44-46].

\section{Safety of long term use of probiotics or synbiotics containing formula}

The way companies address the question on safety of long term consumption of probiotics, synbiotics of infant formula could not be established. Safety of long term use is an important issue since majority of consumers of probiotics, synbiotics containing formula and baby foods use these products for more than a year. According to ESPGHAN committee on nutrition, there is a lack of published evidence on the clinical benefits and safety from long term consumption of probiotic containing formula $[26,38]$. How the formula and baby food companies educate the consumer on this issue is yet to be determined or observed.

\section{Product viability}

Whether bacteria in retailed probiotics or synbiotics containing infant formula remain viable throughout shelf life was not established in this study. There are few reports on the stability of probiotics in powdered formula for infants and toddlers [47]. Several studies have conducted long term stability tests on bifidobacteria in powdered formula and results show the viability of live bacteria (such as bifidobacteria) decreased with length of time in storage and with increase in temperature $[47,48]$. Consumers usually store powdered formula at room temperature. However, the formula may be exposed to high temperatures during transportation, during hot seasons or, in countries with hot weather conditions. If there is a large reduction in viable cell counts of probiotic bacteria, the commercial use of the formula is lost and the consumer does not benefit from the expected probiotic effects [47]. The change in stability at various storage temperatures should be made clear by formula manufacturers.

\section{How companies keep abreast of the latest research on probiotics, prebiotics and synbiotics in infant formula and weaning foods}

How companies keep abreast of the latest research on probiotics, prebiotics and synbiotics in infants could not be established. This study tried to find out if there are any formal mechanisms in place to ensure that employees or researchers keep abreast of the latest research. The formula and baby food industry needs to be more transparent on this issue.

\section{Limitations}

Sampling frame

Only online electronic databases were used to identify the companies around the world that manufacture infant food products with probiotics, prebiotics or synbiotics. Small regional companies that were not listed in the electronic databases were missed and subsequently not invited to participate in the study. Different methods could have been used to identify small regional companies.

\section{Selection bias (under-coverage bias)}

Efforts were concentrated on inviting people responsible for research and development such as clinical research managers and individual researchers. Other staff such as product managers could have been invited to participate in the study.

\section{Survey participation rates, non-response bias}

Survey participation rates were nil. Many company staffs were cautious after the initial contact and invitation to 
participate in the study. After continued dialogue, they were unwilling to participate in the survey. During telephone conversations with the some company employees, the researchers were perceived to be in collaboration with the competition.

\section{Conclusion}

Due to a poor response rate, no conclusion could be drawn on how the food industry applies evidence gained through probiotics, prebiotics or synbiotics research on infants and children for the benefit of the general paediatric population. More information with greater transparency is needed from the infant formula and baby food companies on how they apply the evidence gained from the extensive research conducted using probiotics, prebiotics and synbiotics on infants and children.

\section{Abbreviations \\ AFSSA: French Food Safety Agency; ${ }^{\circ} \mathrm{C}$ : Degrees centigrade; DHA: Docosahexaenoic acid; ESPGHAN: European Society of Pediatric Gastroenterology, Hepatology and Nutrition; FOS: Fructooligosaccharide; GOS: Galactooligosaccharide; SPSS: Statistical Program for Social Sciences; WHO: World Health Organisation.}

\section{Competing interests}

The authors declared that they have no competing interests.

\section{Authors' contributions}

The authors contributed the following: MM: Developed study protocol (unpublished), contacted companies for information, processed data, developed, edited and critically reviewed the manuscript. TY: Assisted in designing the study and critically reviewed the manuscript. RB: Assisted in designing the study, gave further information to companies when contacted and critically reviewed the manuscript. All authors read and approved the final manuscript.

\section{Acknowledgments}

This study was supported through a grant from the University of Stellenbosch, Faculty of Medicine and Health Sciences. South Africa. The sponsors had no role in study design, data collection, analysis and interpretation, report writing or conclusions reached in this study.

\section{Author details}

'Division of Human Nutrition, Faculty of Medicine and Health Sciences, Stellenbosch University, Stellenbosch, South Africa. ${ }^{2}$ Centre for Evidence-Based Health Care, Faculty of Medicine and Health Sciences, Stellenbosch University, Stellenbosch, South Africa.

Received: 11 October 2013 Accepted: 14 October 2014 Published: 23 October 2014

\section{References}

1. World Health Organization: Essential nutrition Actions: Improving maternal, newborn, infant and young child health and Nutrition. 2013. http://www. who.int/nutrition/publications/infantfeeding/essential_nutrition_actions/ en/index.html. Accessed 2014-10-29.

2. UNICEF, WHO, UNESCO, UNFPA, UNDP, UNAIDS, WFP, World Bank: Facts of life. Fourth Edition. 2010. http://www.who.int/nutrition/publications/ infantfeeding/factsoflife/en/index.html. Accessed 2014-10-29.

3. Allain A, Kean YJ: The youngest market. Baby food peddlers undermine breastfeeding, Multinational Monitor. July- August 2008, 17 - 22. 2008.

4. Jones G, Steketee RW, Black RE, Bhutta ZA, Morris SS, The Bellagio Child Survival Group: How many deaths can we prevent this year? Lancet 2003, 362:65-71.

5. World Health Organization: Infant and young child feeding. Model chapter for textbooks for medical students and allied health professionals. 2009. http://whqlibdoc.who.int/publications/2009/9789241597494_eng.pdf. Accessed 2014-10-29.

6. Rai D, Larson B: Driving research in infant and children's nutrition: a perspective on industry. Am J Clin Nutr 2009, 89:1530S-1532S.

7. Adiv OE, Berant M, Shamir R: New supplements to infant formulas. Pediatr Endocrinol Rev 2004, 2:216-224.

8. Barile D, Guinard J, Meyrand M, Bruce German J: Examining bioactive components of milk. complex oligosaccharides (part 1). Agro Food Ind Hi Tech 2011, 22:34-36.

9. Vandenplas Y, De Greef E, Devreker T, Veereman-Wauters G, Hauser B: Probiotics and prebiotics in infants and children. Curr Infect Dis Rep 2013, 15(3):251-262.

10. Gourbeyre P, Denery S, Bodinier M: Probiotics, prebiotics, and synbiotics: Impact on the gut immune system and allergic reactions. J Leukoc Biol 2011, 89(5):685-695.

11. Parvez S, Malik KA, Kang SA, Kim HY: Probiotics and their fermented food products are beneficial for health. J App/ Microbiol 2006, 100:1171-1185.

12. Underwood MA, Salzman NH, Bennett SH, Barman M, Mills DA, Marcobal A, Tancredi DJ, Bevins CL, Sherman MP: A randomized placebo-controlled comparison of 2 prebiotic/probiotic combinations in preterm infants: Impact on weight gain, intestinal microbiota, and fecal short-chain fatty acids. J Pediatr Gastroenterol Nutr 2009, 48(2):216-225.

13. Rampelli S, Candela M, Severgnini M, Biagi E, Turroni S, Roselli M, Carnevali P, Donini L, Brigidi P: A probiotics-containing biscuit modulates the intestinal microbiota in the elderly. J Nutr Health Aging 2013, 17:166-172.

14. Rouhi M, Sohrabvandi S, Mortazavian AM: Probiotic fermented sausage: viability of probiotic microorganisms and sensory characteristics. Crit Rev Food Sci Nutr 2013, 53:331-348.

15. Gawkowski D, Chikindas ML: Non-dairy probiotic beverages: the next step into human health. Benef Microbes 2013, 4:127-142.

16. Nagpal R, Kumar A, Kumar M, Behare PV, Jain S, Yadav H: Probiotics, their health benefits and applications for developing healthier foods: a review. FEMS Microbiol Lett 2012, 334:1-15.

17. Macfarlane GT, Steed H, Macfarlane S: Bacterial metabolism and health related effects of galactooligosaccharides and other prebiotics. J Appl Microbiol 2008, 104:305-344.

18. Cherbut C, Michel C, Raison V, Kravtchenko T, Severine M: Acacia gum is a bifidogenic dietary fibre with high digestive tolerance in healthy humans. Microb Ecol health dis 2003, 15(1):43-50.

19. Schlee M, Harder J, Köten B, Stange EF, Wehkamp J, Fellermann K: Probiotic lactobacilli and VSL\#3 induce enterocyte beta -defensin 2. Clin Exp Immunol 2008, 151(3):528-535.

20. Shah NP: Functional cultures and health benefits. Int Dairy J 2007, 17(11):1262-1277.

21. Boirivant M, Strober W: The mechanism of action of probiotics. Curr Opin Gastroenterol 2007, 23:670-692.

22. Mugambi MN, Musekiwa A, Lombard M, Young T, Blaauw R: Synbiotics, probiotics or prebiotics in infant formula for full term infants: A systematic review. Nutr J 2012, 11:81. doi:10.1186/1475-2891-11-81.

23. Howick J, Chalmers I, Glasziou P, Greenhalgh T, Heneghan C, Liberati A, Moschetti I, Phillips B, Thornton H: The 2011 Oxford CEBM Evidence Levels of Evidence (Introductory Document). Oxford Centre for Evidence-Based Medicine; http://www.cebm.net/index.aspx?o=5653. Accessed 2014-10-29.

24. Howick J, Chalmers I, Glasziou P, Greenhalgh T, Heneghan C, Liberati A, Moschetti I, Phillips B, Thornton H: Explanation of the 2011 Oxford Centre for Evidence-Based Medicine (OCEBM) Levels of Evidence (Background Document). Oxford Centre for Evidence-Based Medicine; http://www.cebm.net/index. aspx?o=5653. Accessed 2014-10-29.

25. OCEBM Levels of Evidence Working Group, Howick J, Chalmers I, Glasziou P, Greenhalgh T, Heneghan C, Liberati A, Moschetti I, Phillips B, Thornton H, Goddard O, Hodgkinson M: The Oxford 2011 Levels of Evidence. Oxford Centre for Evidence-Based Medicine; http://www.cebm.net/index.aspx?o=5653. Accessed 2014-10-29.

26. Braegger C, Chmielewska A, Decsi T, Kolacek S, Mihatsch W, Moreno L, Pieścik M, Puntis J, Shamir R, Szajewska H, Turck D, Van Goudoever J: Supplementation of infant formula with probiotics and/or prebiotics: A systematic review and comment by the ESPGHAN committee on nutrition. J Pediatr Gastroenterol Nutr 2011, 52(2):238-250.

27. Al Faleh KM, Bassler D: Probiotics for prevention of necrotizing enterocolitis in preterm infants. Cochrane Database Syst Rev 2008, Issue 1. Art. No.: CD005496. doi:10.1002/14651858.CD005496.pub2. 
28. Satoh T, Odamaki T, Namura M, Shimizu T, Iwatsuki K, Nishimoto M, Kitaoka M, Xiao J-Z: In vitro comparative evaluation of the impact of lacto-N-biose I, a major building block of human milk oligosaccharides, on the fecal microbiota of infants. Anaerobe 2013, 19(1):50-57.

29. Holscher HD, Faust KL, Czerkies LA, Litov R, Ziegler EE, Lessin H, Hatch T, Sun S, Tappenden KA: Effects of prebiotic-containing infant formula on gastrointestinal tolerance and fecal microbiota in a randomized controlled trial. J Parenter Enteral Nutr 2012, 36(Suppl 1):95S-105S.

30. Guarner F: Studies with Inulin-type fructans on intestinal infections, permeability and inflammation. J Nutr 2007, 137:2568S-2571S.

31. Gibson GR, Nathalie D: Inulin and Oligofructose. New Scientific Developments. Nutr Today 2008, 43:54-59.

32. Buttriss JL: Translating complex science into life-course health promoting strategies. Proc Nutr Soc 2011, 70:38-46.

33. Goldberg JP, Sliwa SA: Communicating actionable nutrition messages: challenges and opportunities. Proc Nutr Soc 2011, 70:26-37.

34. Collier R: Squabble over risks of probiotic infant formula. CMAJ 2009, 181:E46-E47.

35. Cooper PA, Bolton KD, Mokhachane M, Velaphi SC, Mphahlele RM, Bomela $H N$, Monaheng L, Roux P, Haschke-Becher E: Growth of infants born to HIV-positive mothers fed a whey-adapted acidifed starter formula with prebiotics and nucleotides. South Afr J Clin Nutr 2010, 23:90-95.

36. Velaphi SC, Cooper PA, Bolton KD, Mokhachane M, Mphahlele RM, Beckh-Arnold E, Monaheng L, Haschke-Becher E: Growth and metabolism of infants born to women infected with human immunodeficiency virus and fed acidified whey-adapted starter formulas. Nutrition 2008, 24:203-211.

37. World Health Organisation: Safe preparation, storage and handling of powdered infant formula guidelines. 2007. http://www.who.int/foodsafety/ publications/powdered-infant-formula/en/. Accessed 2014-10-29.

38. Agostoni C, Axelsson I, Braegger C, Goulet O, Koletzko B, Michaelsen KF, Rigo J, Shamir R, Szajewska H, Turck D, Weaver LT: Probiotic bacteria in dietetic products for infants: A commentary by the ESPGHAN committee on nutrition. J Pediatr Gastroenterol Nutr 2004, 38(4):365-374.

39. Song F, Parekh S, Hooper L, Loke YK, Ryder J, Sutton AJ, Hing C, Kwok CS, Pang C, Harvey I: Dissemination and publication of research findings: an updated review of related biases. Health Technol Assess 2010, 14:1-5. 39-50.

40. Gunter B, Dickinson R, Matthews J, Cole J: Formula manufacturers' web sites: Are they really non-compliant advertisements? Health Educ 2013, 113:18-27.

41. Hu Y, Sundar SS: Effects of online health sources on credibility and behavioral intentions. Comm Res 2010, 37:105-132.

42. Khoo K, Bolt P, Babl FE, Jury S, Goldman RD: Health information seeking by parents in the internet age. J Paediatr Child Health 2008, 44:419-423.

43. South African Government Notice R9912, Government Gazette 35941 : Regulations relating to foodstuffs for infants and young children. 2012. http://www.greengazette.co.za/notices/foodstuffs-cosmetics-anddisinfectants-act-54-1972-regulations-relating-to-foodstuffs-for-infants-andyoung-children_20121206-GGR-35941-00991.

44. Turck D: Safety aspects in preparation and handling of infant food. Ann Nutr Metabol 2012, 60:211-214.

45. Davanzo R, Giurici N, Demarini S: Hot water and preparation of infant formula: How hot does it have to be to be safe? J Pediatr Gastroentrol Nutr 2010, 50:352-353.

46. Iversen C, Forsythe S: Isolation of enterobacter sakazakii and other enterobacteriaceae from powdered infant formula milk and related products. Food Microbiol 2004, 21:771-777.

47. Abe F, Miyauchi H, Uchijima A, Yaeshima T, Iwatsuki K: Stability of bifidobacteria in powdered formula. Int J Food Sci Technol 2009, 44:718-724.

48. Abe F, Miyauchi H, Uchijima A, Yaeshima T, Iwatsuki K: Effects of storage temperature and water activity on the survival of bifidobacteria in powder form. Int J Dairy Technol 2009, 62:234-239.

doi:10.1186/1756-0500-7-754

Cite this article as: Mugambi et al: Application of evidence on probiotics, prebiotics and synbiotics by food industry: a descriptive study. BMC Research Notes 2014 7:754

\section{Submit your next manuscript to BioMed Central and take full advantage of:}

- Convenient online submission

- Thorough peer review

- No space constraints or color figure charges

- Immediate publication on acceptance

- Inclusion in PubMed, CAS, Scopus and Google Scholar

- Research which is freely available for redistribution 